\title{
Pemanfaatan Taman Kota Lumintang Sebagai Aktifitas Leisure And Recreation Bagi Remaja Kota Denpasar
}

Thalia Natinska Suriyadi a, 1, Ida Ayu Suryasih a, 2

1 thalianatinska@gmail.com,2idaayusuryasih@unud.ac.id

a Program Studi S1 Destinasi Pariwisata, Fakultas Pariwisata,Universitas Udayana, Jl. Dr. R. Goris, Denpasar, Bali 80232 Indonesia

\section{Abstract}

The youth are known to have various activities in their daily lives. a lot of them needed the time to clear their mind from the stress. Many teenagers visit the Lumintang City Park during their spare time to recharge and reinvigorate their energy with various recreational activities. The main purpose of conducting this study is to ascertain the utilization of Lumintang City Park and the significance of recreation obtained by the youth following their recreational activities at Lumintang City Park. Data were collected through observation and questionnaire, and to determine sample using the quota sample to the tune of 50 respondents.

The result of the conducted study had shown that Lumintang City Park is utilized by the youth as a place to exercise, lounge around, enjoy the evening atmosphere, cure boredom, and many other activities, with a relatively dominating advantage specifically in the utilization of Lumintang City Park as a place to exercise. Moreover, the significance of the recreation obtained by the youth in the wake of their activities at Lumintang City Park is dominated by recreation and well-being.

Keywords: : city park, leisure and recreation, youth

\section{PENDAHULUAN}

Remaja pada masa kini memiliki kegiatan yang sangat padat sehingga mereka terus sibuk sepanjang hari. Remaja memiliki aktifitas yang banyak dalam kesehariannya. Remaja dengan umur dari 13-18 tahun adalah remaja pada masa transisi dan pencarian jati diri, yang karenanya sering melakukan perbuatan-perbuatan yang baru. Tidak sedikit remaja melakukan hal-hal yang nakal, namun masih banyak remaja yang melakukan aktifitas yang positif. Setelah disibukan oleh tugas-tugas sekolah maupun kuliah serta kegiatan yang dilakukan mereka diluar dari jam belajar, banyak remaja yang mengambil kelas tambahan atau ekstrakulikuler sehingga membuat jadwal remaja semakin padat. Banyak cara yang dilakukan para remaja untuk membuat waktu luang mereka menjadi bermanfaat agar bisa menghilangkan stres dan juga menyegarkan pikiran dari pekerjaan yang selama ini mereka lakukan. Ada yang melakukan hobinya, meluangkan waktu untuk bertemu dengan keluarga, berolahraga, ataupun mengunjungi tempat-tempat hiburan serta berekreasi.leisure and recreation menjadi pemanfaatkan waktu luang yang dimiliki oleh seseorang ataupun sekelompok manusia untuk melakukan kegiatan rekreasi ke suatu tempat. Pada saat akhir pekan ataupun liburan banyak remaja yang melakukan rekreasi bersama teman maupun keluarganya. Ada yang hanya berekreasi di kota nya ada juga yang keluar kota untuk menikmati rekreasinya. Denpasar merupakan ibu Kota Provinsi Bali, memiliki beberapa tempat rekreasi yang sering di kunjungi masyarakat lokal untuk melakukan aktivitas rekreasi di waktu luang mereka, seperti Mall level 21, Ramayana Department Store, Matahari Duta Plaza, Lapangan Renon, Lapangan Puputan, Taman Kota Lumintang, Hardys, dan Tiara Dewata. Diantara tempat rekreasi yang ada di Kota Denpasar Taman Kota Lumintang. Taman kota merupakan lahan terbuka yang berfungsi sosial dan estetik sebagai sarana kegaitan rekreatif, edukasi atau kegiatan lain pada tingkat kota. Taman Kota Lumintang merupakan taman kota yang dikunjungi oleh masyarakat untuk melakukan aktivitas leisure and recreation.

Banyak remaja sekitar sering mengunjungi Taman Kota Lumintang ini untuk melakukan rekreasi. Taman Kota Lumintang ini banyak dikunjungi oleh remaja saat pagi hari dan sore hari untuk melakukan olaharaga. Bedasarkan fenomena leisure and recreation yang ada di Taman Kota Lumintang ini dan melihat banyak remaja yang melakukan aktivitas leisure and recreation, hal tersebut mendorong untuk melakukan penelitian yang berfokus pada apa manfaat melakukan aktifitas leisure and recreation bagi remaja di Taman Kota Lumintang serta apa makna yang didapat setelah melakukan aktivitas leisure and recreation bagi remaja di Taman Kota Lumintang. 


\section{KEPUSTAKAAN}

\section{1 tinjauan penelitian sebelumnya}

Hasil penelitian sebelumnya yang terkait dengan leisure and recreation pertama penelitian yang dilakukan oleh Mashuri (2005)Pada penelitian tersebut membahas tentang objek wisata ubalan sebagai sarana leisure and recreation yang ada di desa padusan kabupaten mojokerto jawatimur. Menjelaskan tentang motivasi dari pengunjung yang datang di objek wisata ubalan dan juga menjelaskan karakteristik pengunjung di objek wisata Ubalan.penelitian ini memiliki fokus yang sama yaitu sama-sama berfokus pada leisude and recreation namun dengan lokus yang berbeda.

\subsection{Tinjauan Konsep}

\subsubsection{Konsep leisure and recreation}

Marpaung (2000) menjelaskan bahwa waktu luang adalah sisa waktu selain kegiatan rutin sehari-hari yang dilakukan oleh seseorang. Sedangkan yang dimaksud dengan rekreasi adalah pemanfaatan waktu luang untuk istirahat santai dan bersenang-senang guna mengembalikan dan meningkatkan kesegaran dan kesehatan jasmani dan rohani, sebagai akibat kesibukan dan rutinitas pekerjaan seharihari.

Leisure atau waktu luang adalah segala kegiatan atau aktifitas yang terbentuk dari segala kegiatan yang bersifat menghibur atau mendidik. Pernyataan tersebut didasarkan oleh pengakuan dari pihak The Internasional Group of theSocial Science of Leisure, yang menyatakan waktu luang berisikan berbagai macam kegiatan yang mana seseorang akan mengikuti keinginannya sendiribaik untuk beristirahat, menghibur diri sendiri, menambah pengetahuan atau mengembangkan keterampilannya secara objektif atau untuk meningkatkan keikutsertaan bermasyarakat.

MenurutMerpaung (2000) menjelaskan bahwa Recreation atau rekreasi adalah suatu kegiatan pemanfaatan waktu luang guna untuk bersantai,istirahat, dan bersenang-senang untuk meningkatkan dan mengembalikan kesegaran kesehatan jasmani dan rohani dari kesibukan dan rutinitas pekerjaan sehari-hari. Fungsi dari rekreasi mempunyai fungsi :

1. beristirahat dan bersantai

2. Menghilangkan kebosanan akibat kegiatan dan pekerjaayang bersifat terus-menerus
3. Mengembangkan personality dan pengungkapan fisik, mental, dan spiritual.

\subsubsection{Konsep Makna Rekreasi}

Menurut (Haryono,1978 dalam Arifin, 2005) , ada beberapa makna dari rekreasi yaitu rekreasi sebagai kebutuhan fundamental, rekreasi sebagai human right, rekreasi dan kesehatan, rekreasi character building, rekreasi dan pencegahan tindak kriminal, rekreasi dan pendidikan, rekreasi dan moral, rekreasi dan ekonomi, rekreasi dan politik, rekreasi dan peranan pemerintah. Namun dalam penelitian ini peneliti hanya menggunakan enam makna rekreasi yang disesuaikan dengan remaja.

\subsubsection{Konsep Pengunjung}

Menurut pasal 5 resolusi dewan ekonomi dan sosial perserikatan bangsa-bangsa no.870

"pengunjung adalah setiap orang yang mengunjungi suatu negara yang bukan tempat tinggalnya yang biasa, dengan alasan apapun juga,kecuali mengusahakan suatu pekerjaan yang dibayar oleh negara yang di kunjunginya."

International Union of Official Travel Organization (IUOTO), pengunjung adalah setiap orang yang berkunjung ke suatu negara atau tempat tinggal lain dan biasanya dengan maksud apapun kecuali untuk melakukan pekerjaan yang menerima upah.

\subsubsection{Konsep Kependudukan}

Menurut UU.RI.No. 10 tahun 1992, penduduk yaitu orang dalam matranya sebagai pribadi, anggota keluarga,anggota masyarakat, warganegara dan himpunan kuantitas yang bertempat tinggal di suatu tempat dalam batas wilayah Negara pada waktu tertentu.

Penduduk adalah setiap warga negara yang tinggal di daerah dalam waktu enam bulan atau lebih, tetapi ada keinginan untuk menetap ( Tri Setiyaningsih, 2004:13 ).

Menurut Depkes RI (2009) kategori umur terbagi atas, masa balita $=0-5$ tahun, masa kanak-kanak $=5-11$ tahun, masa remaja awal = 12-16 tahun, masa remaja akhir $=17-25$ tahun, masa dewasa awal $=26-35$ tahun, masa dewasa akhir $=36-45$ tahun, masa lansia awal $=46-55$ tahun, masa lansia akhir $=56-65$ tahun, masa manula $=65-$ sampai atas. 


\section{METODE PENELITIAN}

\section{1 Ruang Lingkup}

Untuk memperjelas serta membatasi masalah yang ada pada penelitian ini di butuhkan batasan,untuh segi lokasi lingkup penelitian dibatasi hanya di Taman Kota Lumintang saja. Sedangkan lingkup penelitian dari segi permasalahan yaitu pemanfaatan Taman Kota Lumintang sebagai aktivitas leisure and recreation yang dimaksud dalam penelitian ini seperti duduk santai, berolahraga, menikmati susasan sore dan menghilakan kebosanan. Selain itu makna rekreasi yang didapat dari pengunjung setelah melakukan aktifitas leisure and recreation di Taman Kota Lumintang bedasarkan 10 makna hanya di ambil menurut Haryono(1978) dalam Arifin, (2005) yaitu Rekreasi sebagai kebutuhan fundamental, Rekreasi sebagai human right, Rekreasi dan kesehatan, Rekreasi danpencegahan tindak criminal,Rekreasi dan Pendidikan, Rekreasi dan moral .

\subsection{Teknik Pengumpulan Data}

Untuk mendapatkan data-data yang dibutuhkan ada beberapa teknik pengumpulan data yang digunakan yaitu observasi dan kuisioner. Yang menjadi objek observasi dalam penelitian ini adalah Taman Kota Lumintang kota Denpasar Bali. Teknik observasi dalam penelitian ini untuk mengetahi kondisi eksisting dan potensi yang dimiliki dari Taman Kota Lumintang.

Kuisioner dalam penelitian ini merupakan Penyebaran kuesioner ini ditujukan kepada pengunjung khusus remaja taman kota lumintang.kuesioner ini mengambil jumlah sampel sebanyak 50 responden dengan menggunakan teknik pengambilan sampel yaitu accidental sampling.

\section{3 Teknik Analisis Data}

Teknis analisis data yang digunakan untuk penelitian ini menggunkan metode analisis deskriptif kualitatif. Teknis analisis data yang digunakan adalah teknik analisis data model Miles dan Huberman dalam sugiyono (2014) dengan cara mereduksi data, dimana peneliti merangkum dan memilah hal-hal pokok. Dengan mereduksi data akan memberikan gambaran umum. Kedua penyajian data Setelah data direduksi, maka langkah selanjutnya adalah penyajian data. Melalui penyajian data, akan memudahkan untuk mengerti apa yang terjadi, merencanakan kerja selanjutnya dengan apa yang telah dipahami tersebut. Ketiga penarikan kesimpulan dimana peneliti menarik kesimpulan untuk memperoleh pemahaman tentang pemanfaatan dan makna rekreasi yang didapatkan pengunjung setelah mengunjungi taman kota lumintang denpasar.

Untuk Data yang telah diperoleh dari 50 responden dianalisis menggunakan teknik analisis statistik deskriptif yang dikemukakan oleh Santoso (2014). Statistik deskriptif merupakan teknik analisis data kuantitatif yang terbagi menjadi pertama Meringkas data mentah menjadi data yang baik dan teratur menggunakan analisis frekuensi dengan alat bantu SPSS atau menggunakan rumus :

$n=\frac{\text { total responden memilih jawaban }}{\text { total responden }} \times 100 \%$

Kedua Menyajikan data yang telah diubah dalam bentuk tabel dan diagram atau grafik. Dan yang terakhir Menjelaskan arti dari tabel dan diagram atau grafik yang sudah disajikan dengan analisis deskriptif. Sehingga bisa menarik kesimpulan atas makna rekreasi yang didapatkan pengunjung setalah mengunjungi taman kota lumintang denpasar.

\section{HASIL DAN PEMBAHASAN}

\section{1 Lokasi Penelitian}

Taman Kota Lumintang merupakan salah satu taman kota yang ada di Kota Denpasar. Taman Kota Lumintang memiliki luas $30.000 \mathrm{~m}^{2}$. Taman Kota Lumintang berdiri bersamaan dengan hari jadi Kota Denpasar yang bertepatan pada tanggal 27 Februari 1999. Sekitar tahun 1960-an Taman Kota Lumintang merupakan bekas pusat pemerintahan Badung dan pernah terjadi pengrusakan sehingga dijadikan Taman Kota oleh Pemerintah. Diantara taman kota yang ada di Denpasar, Taman Kota Lumintang memiliki suatu atraksi yang menjadi salah satu penarik bagi pengunjung dan berbeda dari taman kota lain yang ada di Denpasar. Taman Kota Lumintang memiliki kolam dengan diameter 15 sampai 20 meter yang ditengahtengahnya ada air mancur yang bisa menari-nari diiringi oleh lampu kelap-kelip. Pertunjukan air mancur ini sendiri dibuka sejak akhir tahun 2015 lalu. Air mancur ini bisa dinikmati oleh pengunjung pada hari sabtu dan minggu pukul 06.00 sampai pukul 09.00 WITA. 


\subsection{Karakteristik remaja di Taman Kota Lumintang}

Dalam penelitian ini, karakteristik dari remaja yang berkunjung ke Taman Kota Lumintang dijelaskan bedasarkan beberapa aspek. Aspek - aspek ini yaitu jenis kelamin, umur, pekerjaan, dan pendidikan. Melihat dari aspek jenis kelamin remaja kota Denpasar yang banyak mengunjungi Taman Kota lumintang didominasi oleh jenis kelamain perempuan, Hal tersebut disebabkan karena remaja perempuan saat mengunjungi Taman Kota Lumintang bersama dengan teman-temannya dan karena di Taman Kota Lumintang memiliki tempat berfoto yang banyak diminati oleh remaja khususnya remaja perempuan.

\section{Tabel 1}

Jenis kelamin remaja di Taman Kota Lumintang

\begin{tabular}{|c|c|c|c|}
\hline No & Jeniskelamin & $\begin{array}{c}\text { Responden } \\
\text { (orang) }\end{array}$ & $\begin{array}{c}\text { Prensentase } \\
(\%)\end{array}$ \\
\hline 1 & Laki-laki & 19 & 38 \\
\hline $\mathbf{2}$ & Perempuan & $\mathbf{3 1}$ & $\mathbf{6 2}$ \\
\hline \multicolumn{2}{|c|}{ Total } & 50 & 100 \\
\hline
\end{tabular}

Sumber: diolah dari data penelitian 2017

Jika melihat dari aspek umur remaja Kota Denpasar yang mengunjungi Taman Kota Lumintang di dominasi oleh umur 17-25 tahun. Hal tersebut disebabkan karena remaja akhir sudah memiliki aktifitas yang monoton sehingga remaja akhir banyak melakukan rekreasi untuk menghilangkan kebosanan dan juga memanfaatkan waktu luangnya sebagai suasana hati atau mental yang positif.

Tabel 2

Umur Remaja di Taman Kota Lumintang

\begin{tabular}{|c|c|c|c|}
\hline No & Umur & $\begin{array}{c}\text { Responden } \\
\text { (orang) }\end{array}$ & $\begin{array}{c}\text { Prensentase } \\
(\%)\end{array}$ \\
\hline 1 & $12-16$ & 19 & 38 \\
\hline 2 & $17-25$ & 31 & 62 \\
\hline & Total & 50 & 100 \\
\hline
\end{tabular}

Sumber: diolah dari data penelitian 2017

Aspek selanjutnya adalah aspek pekerjaan dimana remaja Kota Denpasar yang mengunjungi Taman Kota Lumintang sebagian besar merupakan pelajar/mahasiswa. Hal ini disebabkan karena remaja yang berstatus pelajar/mahasiswa lebih memanfaatkan waktu luang yang dimiliki sebagai aktifitas karena para pelajar atau mahasiswa melakukan aktifitas rekreasi yang bersifat menghibur atau mendidik.

Tabel 3

Pekerjaan remaja di Taman Kota Lumintang

\begin{tabular}{|c|c|c|c|}
\hline $\begin{array}{c}\mathrm{N} \\
\mathrm{o}\end{array}$ & Pekerjaan & $\begin{array}{c}\text { Responde } \\
\text { n (orang) }\end{array}$ & $\begin{array}{c}\text { Prensenta } \\
\text { se (\%) }\end{array}$ \\
\hline 1 & Bekerja & 5 & 10 \\
\hline 2 & Tidak bekerja & 0 & 0 \\
\hline $\mathbf{3}$ & $\begin{array}{c}\text { Pelajar/mahasis } \\
\text { wa }\end{array}$ & $\mathbf{4 5}$ & $\mathbf{9 0}$ \\
\hline \multicolumn{2}{|c|}{ Total } & 50 & 100 \\
\hline
\end{tabular}

Sumber: diolah dari data penelitian 2017

Setelah dilihat dari aspek pekerjaan peneliti melihat aspek pendidikan. Dimana pada aspek pendidikan remaja Kota Denpasar yang mendominasi Taman Kota Denpasar adalah pelajar SMA (sekolah menengah atas). Hal tersebut disebabkan karena pelajar SMA memanfaatkan Taman Kota Lumintang untuk tempat berkumpul dengan teman saat pulang sekolah. Selain itu mereka dapat beristirahat dan bersantai di Taman Kota Lumintang serta menghilangkan penat setelah belajar di sekolah.

Tabel 4

Pendidikan remaja di Taman Kota Lumintang

\begin{tabular}{|c|c|c|c|}
\hline No & Pendidikan & $\begin{array}{c}\text { Responden } \\
\text { (orang) }\end{array}$ & $\begin{array}{c}\text { Prensentase } \\
(\%)\end{array}$ \\
\hline 1 & $\begin{array}{c}\text { Tidak } \\
\text { bersekolah }\end{array}$ & 0 & 0 \\
\hline 2 & SD/MI & 1 & 2 \\
\hline 3 & SMP & 10 & 20 \\
\hline 4 & SMA & 21 & 42 \\
\hline 5 & Diploma & 1 & 2 \\
\hline 6 & Sarjana 1 & 17 & 34 \\
\hline & Total & 50 & 100 \\
\hline
\end{tabular}

Sumber: diolah dari data penelitian 2017

\subsection{Pemanfaatan dan Makna Rekreasi di Taman Kota Lumintang \\ 4.3.1Pemanfaatan Taman Kota Lumintang \\ Sebagai sarana leisure and recreation} Taman Kota Lumintang banyak dikunjungi oleh remaja denpasar untuk dijadikan tempat berekreasi. Pengunjung juga mendapatkan kepuasan di saat melaksanakan rekreasinya yang dapat memanfaatkan Taman Kota Lumintang sebagai tempat untuk mengisi waktu luang. Berikut tabel yang berisi gambaran pemanfaatan Taman Kota Lumintang yang diperoleh dari remaja yang mengunjungi Taman Kota Lumintang. 
Tabel 5

Aktifitas pengunjung di Taman Kota Lumintang

\begin{tabular}{|c|c|c|c|}
\hline No & Aktifitas & $\begin{array}{c}\text { Responden } \\
\text { (orang) }\end{array}$ & $\begin{array}{c}\text { Prensentase } \\
(\%)\end{array}$ \\
\hline 1 & Olahraga & 19 & 38 \\
\hline 2 & Duduk santai & 9 & 18 \\
\hline 3 & $\begin{array}{c}\text { Menikmati } \\
\text { suasana sore }\end{array}$ & 7 & 14 \\
\hline 4 & $\begin{array}{c}\text { Menghilangkan } \\
\text { kebosanan }\end{array}$ & 10 & 20 \\
\hline 5 & lainnya & 5 & 10 \\
\hline & Total & 50 & 100 \\
\hline
\end{tabular}

Sumber: diolah dari data penelitian 2017

Dari data aktifitas yang dilakukan remaja di Taman Kota Lumintang dapat diketahui bahwa remaja yang datang sebagian besar memanfaatkan Taman Kota Lumintang sebagai tempat untuk berolahraga. Karena Taman Kota Lumintang memiliki jogging track yang bisa digunakan untuk jogging. Selain itu Taman Kota Lumintang juga dilengkapi dengan fasilitas olahraga yang bisa digunakan untuk melakukan workout. Selain itu Taman Kota Lumintang juga berada di tengah kota dan berdekatan dengan rumah masyarakat sekitar, hal ini pula yang mendukung pemanfaatan waktu luang dapat dilakukan dan terwujudnya aktifitas yang di harapkan oleh remaja Kota Denpasar.

\subsubsection{Makna Rekreasi Taman Kota Lumintang}

Tabel 6

Makna rekreasi bagi pengunjung Taman Kota Lumintang

\begin{tabular}{|c|c|c|c|}
\hline $\begin{array}{c}\mathrm{N} \\
\mathrm{o}\end{array}$ & Makna rekreasi & $\begin{array}{c}\text { Respond } \\
\text { en } \\
\text { (orang) }\end{array}$ & $\begin{array}{c}\text { Prensenta } \\
\text { se (\%) }\end{array}$ \\
\hline 1 & $\begin{array}{c}\text { Rekreasisebagaikebutu } \\
\text { han fundamental }\end{array}$ & 7 & 14 \\
\hline 2 & $\begin{array}{c}\text { Rekreasisebagaihuman } \\
\text { right }\end{array}$ & 6 & 12 \\
\hline $\mathbf{3}$ & $\begin{array}{c}\text { Rekreasi dan } \\
\text { kesehatan }\end{array}$ & $\mathbf{3 1}$ & $\mathbf{6 2}$ \\
\hline 4 & $\begin{array}{c}\text { Rekreasi } \\
\text { danpencegahan }\end{array}$ & 1 & 2 \\
\hline
\end{tabular}

\begin{tabular}{|c|c|c|c|}
\hline & tindakkriminal & & \\
\hline 5 & $\begin{array}{c}\text { Rekreasi dan } \\
\text { pendidikan }\end{array}$ & 3 & 6 \\
\hline 6 & Rekreasi dan moral & 2 & 4 \\
\hline \multicolumn{2}{r|}{ Total } & 50 & 100 \\
\hline
\end{tabular}

Sumber: diolah dari data penelitian 2017

Bedasarkan tabeldapat di jelaskan bahwa makna rekreasi yang di dapatkan oleh remaja Kota Denpasar di Taman Kota Lumintang sebagai berikut:

1. Rekreasi sebagai Kebutuhan Fundamental

Dengan melakukan kegiatan rekreasi seseorang dapat menikmati indahnya kehidupan. Dari 50 remaja yang di jadikan sampel yang melakukan rekreasi di Taman Kota Lumintang sebanyak 7 remaja atau 14\% merasakan rekreasi sebagai kebutuhan fundamental. Hal ini dapat dirasakan karena remaja yang melakukan aktifitas rekreasi di Taman Kota Lumintang mereka dapat bersantai dan berkumpul bersama teman, keluarga serta pasangan dan melakukan aktifitas rekreasi yang mereka senangi hal ini terjadi karena keinginan dari remaja sendiri dan tanpa adanya paksaan dari pihak lain. Rekreasi yang di lakukan pada saat waktu luang di Taman Kota Lumintang sebagai fundamental juga mempunyai arti lain bagi remaja yang datang kesana dimana para remaja ingin melepas lelah dari aktifitas seharihari dan ingin mendapatkan ketenangan dan melakukan kegiatan yang mereka senangi.

2. Rekreasi sebagai Human Right

Menikmati waktu luang merupakan hak seseorang selama kegiatan yang dilakukan tersebut tidak mengganggu ketenangan umum. Dari 50 remaja yang dijadikan sampel sebanyak 6 remaja atau 12\% merasakan makna rekreasi sebagai human right. Hal ini dapat dirasakan oleh remaja karena Taman Kota Lumintang merupaka tempat yang bisa untuk berjalan santai menghilangkan kebosanan yang dapat membuat remaja tersebut merasakan rasa senang.

\section{Rekreasi dan Kesehatan}

Dengan rekreasi seseorang dapat melupakan masalah kesehatan yang dihadapinnya dan dengan demikian dapat 
memulihkan kembali semangat serta mengurangi beban yang dirasakan oleh seseorang. Dari 50 remaja yang dijadikan sampel sebanyak 31 remaja atau $62 \%$ merasakan rekreasi dan kesehatan.

Bagi para remaja yang melakukan olahraga di Taman Kota Lumintang, remaja merasakan manfaat bagi kesehatan mereka. Bagi remaja, Taman Kota Lumintang juga merupakan tempat alternative untuk melakukan olahraga ditambah dengan adanya alat-alat untuk melakukan workout di temani dengan suasana yang tenang sehingga dapat memulihkan semangat remaja.

4. Rekreasi dan Pencegahan Tindak Kriminal

Dengan melakukan kegiatan rekreasi, seseorang dapat menumpahkan keinginannya pada hal-hal yang berguna / lebih bermanfaat yang pada akhirnya dapat menekan keinginan untuk melakukan aktivitas yang bersifat kriminal atau kejahatan. Remaja cenderung memiliki emosi yang masil labil sehinga membuat emosi menjadi naik turun dan memancing kejahatan. Dari 50 remaja yang dijadikan sample sebanyak 1 orang atau 2\% merasakan rekreasi sebagai pencegahan tindak kriminal.

Hal ini dikarenakan dengan melakukan aktifitas rekreasi dan melakukan hal yang lebih berguna sehingga remaja bisa berbagi cerita, bersantai, dan becanda sehungga remaja bisa mestabilkan emosi dan tidak melakukan tindak kejahatan.

\section{Rekreasi dan Pendidikan}

Pendidikan dapat diperoleh dimana saja, baik itu didapat secara formal maupun non formal. Salah satunya adalah dengan mempelajari dan melakukan kegiatan rekreasi. Dari 50 remaja yang dijadikan sampel sebanyak 3 remaja atau $6 \%$ memilih rekreasi dan pendidikan.

Taman Kota Lumintang memiliki sarang burung yang bisa dijadikan edukasi bagi remaja selain bisa melihat burung dan memberinya makan, dengan melakukan rekreasi remaja juga bisa merasakan pendidikan non formal dengan bertemu orang baru dan juga bisa memperdalam kegiatan yang disenangi.

6. Rekreasi dan Moral
Dengan adanya kegiatan rekreasi, maka seseorang dapat mendapatkan kembali kepercayaan dirinya serta dapat mengangkat moral yang telah jatuh. Dari 50 remaja yang dijadikan sampel sebanyak 2 remaja atau 4\% memilih rekreasi dan moral. Karena dengan melakukan rekreasi remaja bisa meningkatkan kepercayaan diri dalam mengahadapi masalah yang dihadapi dan pembentukan moral yang bagus dan membantu memberikan moral yang positif bagi remaja.

Dari ke enam makna rekreasi yang di dapatkan remaja setelah melakukan aktifitas di Taman Kota Lumintang, yang paling di rasakan remaja adalah makna rekreasi dan kesehatan. Hal ini disebabkan karena remaja yang melakukan aktifitas rekreasi di Taman Kota Lumintang mendapatkan kesehatan yang mereka inginkan. Dengan dilakukannya aktifitas olahraga di Taman Kota Lumintang remaja dapat memulihkan kembali semangat dan juga mengurangi beban yang di rasakan oleh remaja itu sendiri.

\section{PENUTUP \\ 5.1 Simpulan}

Taman Kota Lumintang memiliki manfaat bagi remaja di Kota Denpasar serta remaja juga mendapatkan makna rekreasi setelah melakukan aktifitas rekreasi untuk mengisi waktu luang mereka.Manfaat dengan adanya Taman Kota Lumintang sendiri bagi remaja adalah para remaja bisa melakukan olahraga, menikmati suasana sore, duduk santai, menghilangkan kebosanan serta melakukan aktifitas lainnya di Taman Kota Lumintang ini.Pemanfaatan Taman Kota Lumintang lebih banyak dimanfaatkan para remaja sebagai tempat untuk berolahraga.

Setelah melakukan aktifitas dan berekreasi di Taman Kota Lumintang, remaja juga mendapatkan makna yang dapat dirasakan. Makna rekreasi terbagi menjadi enam yaitu : rekreasi sebagai kebutuhan fundamental, rekreasi sebagai human right, rekreasi dan kesehatan, rekreasi dan pencegahan tindak kriminal, rekreasi dan pendidikan, serta rekreasi dan moral. Dari keenam makna rekreasi yang paling banyak di rasakan oleh remaja setelah melakukan aktifitas rekreasi di Taman Kota Lumintang adalah rekreasi dan kesehatan. 


\subsection{Saran}

Sebaiknya pemerintah atau dinas yang mengelola Taman Kota Lumintang lebih merawat rumput yang ada disana agar para pengunjung lebih nyaman saat duduk bersantai di taman. pemerintah mengadakan acara ataupun event yang bisa menambah wawasan dan softskill remaja Kota Denpasar.

\section{DAFTAR PUSTAKA}

Audifax, 2008. Re-search. Yogyakarta : Jalasutra.

Arifin, Miftahol.2005.Pemanfaatan taman bunga kota sebagai aktivitas leisure and recreation di kabupaten Sumenep Madura Provinsi Jawa timur. laporan akhir P.S Pariwisata Universitas Udayana.

Chandra, Ari.2012. Studi home range penggunaan taman kota studi kasus lapangan puputan mangarana niti mandala, denpasar bali. Jurnal argoekoteknologi vol.1 No.2, 2012.

Kusmayadi, dan Endar Sugiarti. 2000. Metodologi Penelitian Dalam Bidang Kepariwisataan. Jakarta: Gramedia Pustaka.

Madjid, K. A., \& Suryasih, I. A. 2015. Pemanfaatan Pantai Perancak Sebagai Lokasi Aktivitas Leisure And Recreation di Desa Tibubeneng. Jurnal Destinasi Pariwisata, Vol.3 No. 2, 35-39.

Margono.2004. Metodologi Penelitian Pendidikan. Jakarta: Rineka Cipta.

Marpaung,Happy.2000.PengetahuanKepariwisataan.Band ung:Alfabeta.

Moleong. 2012. Metodologi penelitian kualitatif. Bandung: PT.remaja rosdakarya.

Mukhtar.2013.metode penelitian deskriptif kualitatif.Jakarta: GP Press Group.

Mansuri, Aan Chamil.2005. potensi objek wisata ubalan sebagai sarana leisure and recreation di desa padusan kabupaten mojokerto jawatimur.laporan akhir P.S Pariwisata Universitas Udayana.

Gunawan, Imam.2013. Metode Penelitian Kualitatif:teori dan praktek.Jakarta:PT. Bumi Aksara.

Wardiyanta.2006.MetodePenelitianPariwisata.Yogyakarta: andi yogyakarta

Santoso, Singgih. 2014. Panduan Lengkap SPSS Versi 20 Edisi Revisi. Jakarta : PT Elex Media Komputindo.

Setiyani, Ari. 2012. Mengisi Waktu Luang Pada Siswa SMA Negeri 1 Perancak. Skripsi. Fakultas Ilmu Pendidikan Yogyakarta

Sevilla, Consuelo G. et. Al. 2007. Research Methods. Quezon City : Rex Printing Company.

Sugiyono. 2010. Metode Penelitian Kuantitatif, Kualitatif dan R\&D ( Research and Development). Bandung: Alfabeta.

Sumber Lain:

http://andiybt.blogspot.co.id/2011/09/pariwisata.html

http://pendidikanjasmani13.blogspot.co.id/2013/02/pen

gertian-rekreasi-dan-waktu-luang.html
Untuk masyarakat lokal sebaiknya tetap menjaga apa yang telah difasilitasi oleh pemerintah dan ikut merawat Taman Kota Lumintang agar memberikan aktifitas rekreasi yang lebih baik lagi. 